\title{
ANALYSIS OF VeHICle PATH RAdII ON HORIZONTAL CURVES FOR TWO-LANE RURAL ROADS
}

\author{
Biljana Maljkovic \& Drazen Cvitanic
}
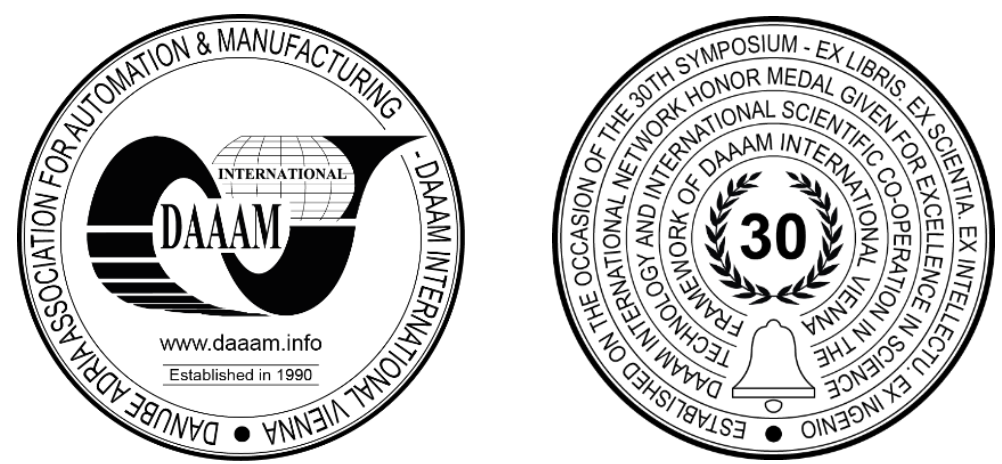

This Publication has to be referred as: Maljkovic, B[iljana] \& Cvitanic, D[razen] (2021). Analysis of Vehicle Path Radii on Horizontal Curves for Two-Lane Rural Roads, Proceedings of the 32nd DAAAM International Symposium, pp.0719-0723, B. Katalinic (Ed.), Published by DAAAM International, ISBN 978-3-902734-33-4, ISSN 1726-9679, Vienna, Austria

DOI: $10.2507 / 32$ nd.daaam.proceedings. 100

\begin{abstract}
In order to obtain locations with reduced level of consistency, vehicle path radii on horizontal curves for two-lane rural roads were analysed. The data collected in an experimental survey on a segment of the two-lane state road DC1 in Croatia were used, in which the drives of a representative sample of drivers were recorded with a high frequency GPS device. The stepwise linear regression was used to investigate the possible influence of geometric characteristics of the road on the driver's choice of path radius and no statistically significant correlation was found. The analysis showed that the vehicle path radii were mainly smaller than curve radius (on average for 12\%). The largest deviations of vehicle path radii from designed values were found on sharper curves $(R<150 \mathrm{~m})$, indicating an increased risk of skidding which may be related to the fact that sharp curves are associated with high accident rates.
\end{abstract}

Keywords: vehicle path radius; horizontal curve; design consistency; global positioning system (GPS); vehicle stability.

\section{Introduction}

Four factors mainly affecting road safety, sorted in ascending order are: equipment failure, road design, poor roadway maintenance and driver behaviour [1]. Road accident "black spots" indicate the fact that, in addition to human factor, road characteristics can often be the cause of accidents. Horizontal curves are high-risk locations, i.e. locations where traffic accidents occur more often. More detailed research has shown that there is a relationship between the number of traffic accidents and curvature. Specifically, the accident frequency increases with decreasing curve radius, especially in curves with radii less than $200 \mathrm{~m}$ (Fig. 1.).

Traffic accidents frequently occur due to lack of geometric design consistency, i.e., when road characteristics are not in line with expectations of drivers. A lot of research has been done to explore this concept, resulting in various quantitative measures for evaluation of design consistency. Specifically, when talking about consistency in horizontal curves, vehicle stability should certainly be highlighted as an important consistency measure. Quantitative consistency measure based on vehicle stability is provided by checking the margin of safety (the difference between the limiting value of side friction and side friction demand) [3]. Ensuring vehicle stability is important because insufficient side friction at horizontal curves may result in vehicle skidding or rollover. 


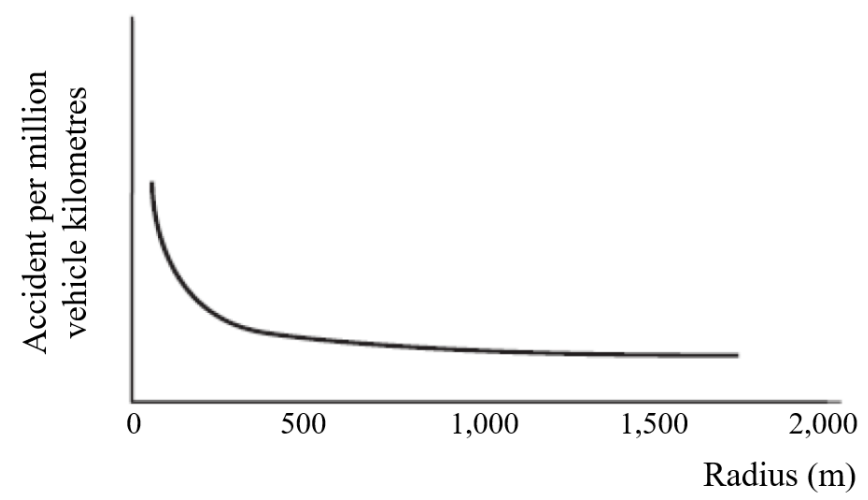

Fig. 1. Relationship between horizontal curve radius and accident risk [2]

Furthermore, most of previous road safety and design consistency studies focused on operating speed, whereas only a few authors were analysing driver behaviour in terms of actual vehicle path radii [4], [5], [6], [7], [8], [9]. Therefore, the aim of this paper is to analyse design consistency in horizontal curves, by comparing design curve radii and actual vehicle path radii, as well as to determine the impact of speed, speed differential and geometric features of the road on driver's choice of vehicle path radius in curve. The path radii were collected in an experimental investigation on a segment of the two-lane state road, conducted as part of [10].

\section{Data collection methodology}

An experimental survey was conducted on a $24 \mathrm{~km}$ long road segment of the state road DC1 (Fig. 2.) to collect the driver behaviour data. High performance GPS device was used to record the test drives of 20 drivers (of different ages and with different driving experiences), performed with their own personal cars. The selected road segment is a twolane rural road with relatively low traffic volume (the average annual traffic is about 1400 veh/day) and with no main intersections what allowed to collect the data in free-flow conditions. The selected road segment consists of alignment elements with a wide range of geometric characteristics: 97 horizontal curves with radii varying from 80 to $1000 \mathrm{~m}$ and 92 tangents with lengths up to $700 \mathrm{~m}$. The survey was conducted under optimal weather conditions (daylight and dry pavement). Based on precisely recorded positions and headings (ten times a second), GPS associated software automatically calculates vehicle path radii:

$R=\frac{57.3 \cdot L}{D_{C}}$

where $L(\mathrm{~m})$ is curve length and $D_{c}$ (degree) is the change in heading. Due to significantly higher accident risk in smallradius curves (as shown in Fig. 1.), as well as the fact that the precision of radius estimating is decreasing with the increase in curve radius [11], only sharper curves (radii from 80 to $315 \mathrm{~m}$ ) were considered. As relevant vehicle path radius for each curve and individual test run, the value of the smallest constant radius was selected, i.e., relatively constant value of the radius (with up to $5 \%$ deviations in curvature) with a driving length of at least 0.5 seconds. As recommended by some authors ([4], [12]), the $15^{\text {th }}$ percentile path radius $\left(R_{15}\right)$ was selected for the critical curve path radius (path radii of only $15 \%$ of drivers are smaller than $R_{15}$ ).

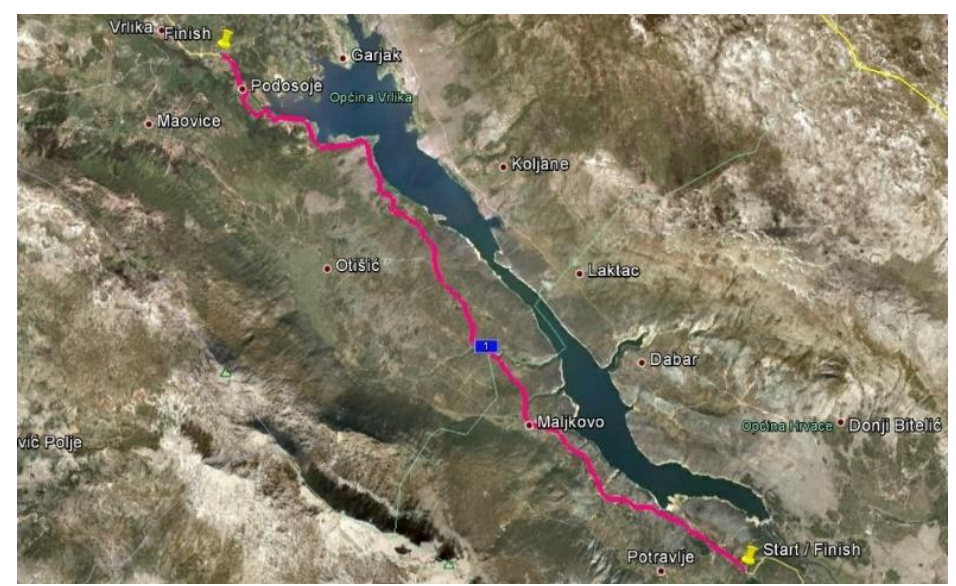

Fig. 2. Segment of the state road DC1 [10] 


\section{Analysis and results}

To improve road design consistency and safety, road characteristics should be consistent with driver's expectations. The road design consistency can easily be checked by comparing the values of driver's behaviour parameters (e.g., vehicle path radius) with the corresponding actual design geometric alignment (e.g., design curve radius), and detecting their differences. So, the collected naturalistic data were used to compare design curve radii and critical $15^{\text {th }}$ percentile path radii. In addition, stepwise linear regression was used to analyse the possible influence of speed, speed differential and geometric characteristics of the road on the driver's choice of vehicle trajectory. The percentage difference between design curve radius and critical $15^{\text {th }}$ percentile vehicle path radius was selected for dependent variable, thus enabling analysis of horizontal curves with different curvatures:

$$
\Delta R=\frac{R-R_{15}}{R} \cdot 100
$$

The following independent variables were considered in the regression procedure: $85^{\text {th }}$ percentile curve speed $V_{85, c}$ $(\mathrm{km} / \mathrm{h}), 85^{\text {th }}$ percentile speed differential $\Delta_{85} V(\mathrm{~km} / \mathrm{h})$, curve radius $R(\mathrm{~m})$, deflection angle $\alpha\left({ }^{\circ}\right)$, slope $s(\%)$, curve length $L_{c}(\mathrm{~m})$, previous and following tangent length $L_{t 1}, L_{t 2}(\mathrm{~m})$, previous and following spiral length $L_{s l}, L_{s 2}(\mathrm{~m})$. Except the above geometric characteristics of the observed curve, speed differential was also considered as an independent variable, representing driver behaviour in the transition between adjacent alignment elements.

At first, the effect of each independent variable was examined by their individual regressions and this preliminary analysis showed that the influence of geometric features of adjacent elements on $\Delta R$ is negligible. Therefore, the regression plots for the following variables are shown in Fig. 3.: curve radius (Fig. 3. a), curve length (Fig. 3. b), deflection angle (Fig. 3. c), curve operating speed (Fig. 3. d) and speed differential - north-south direction (Fig. 3. e). As can be seen from Fig. 3., the selected independent variables do not explain much of the $\Delta R$ variability, while $L_{c}$ has the greatest influence. However, the conducted analysis could provide some regularities about drivers' behaviour. In general, drivers tend to perform path radius sharper than the curve radius, regardless of the driving direction, with critical vehicle path radius on average $12 \%$ smaller than curve radius. Similar results were found in some previous research [8], [9].

The largest range of vehicle path radii values was observed on sharp curves (Fig. 3. a). With the intention of more comfortable ride, in sharp and short curves with small deflection angles, many drivers "cut the curve" performing a path radius greater than the curve radius (Fig. 3. a, b and c). Such manoeuvres could partially be explained by limited sight distance that is characteristic of sharp curves. At the same time, the largest positive values of $\Delta R$ (of even $25 \%$ ) were observed in curves with radii less than about $150 \mathrm{~m}$. Since these are small-radii curves, they are associated with lower operating speeds, regardless of the curve length and deflection angle. In order to achieve more comfortably ride in sharp curves, drivers often underestimate actual curvature. Somewhere along the curve the mistake is realized and is usually corrected by abrupt turn of the steering wheel resulting in path radius much smaller than design curve radius. Negotiating curve with smaller path radius results in an increase of centripetal acceleration and thus the side friction demand. In poor pavement conditions and with inappropriate speed, such sudden turns of the steering wheel can result in vehicle instability and can potentially lead to single-vehicle accident. The greatest path radii inconsistencies (highest values of $\Delta R$ ) were observed in sharp curves $(R<150 \mathrm{~m})$, which indicates an increased risk of skidding, and can be associated with an increased accident rate in small-radii curves (Fig. 1.).

After individual regressions, the stepwise linear regression was performed. Since several independent variables have been analysed, it is necessary to determine which of them are the most significant. Individual regressions (Fig. 3. a, b and $\mathrm{c}$ ) indicate that for some independent variables $\left(R, L_{c}\right.$ and $\left.\alpha\right)$, the approximation withe logarithmic form would be better than the linear one. Therefore, the logarithmic values of these variables were used when performing multiple regression analysis. As expected with respect to the individual regression diagrams, the stepwise regression resulted with only the curve length as independent variable:

$$
\Delta R=8.41 \cdot \ln L_{c}-27.09
$$

Other selected independent variables were excluded from the model because they were found not to contribute significantly to the overall model. The developed model shows that the percentage difference between the curve radius and the critical vehicle path radius increases with increasing curve length. However, although there is a certain dependence between the percentage of the radii difference and curve length, with adjusted coefficient of determination of $\bar{R}^{2}=0.348$, this model could be considered weak and unreliable. 


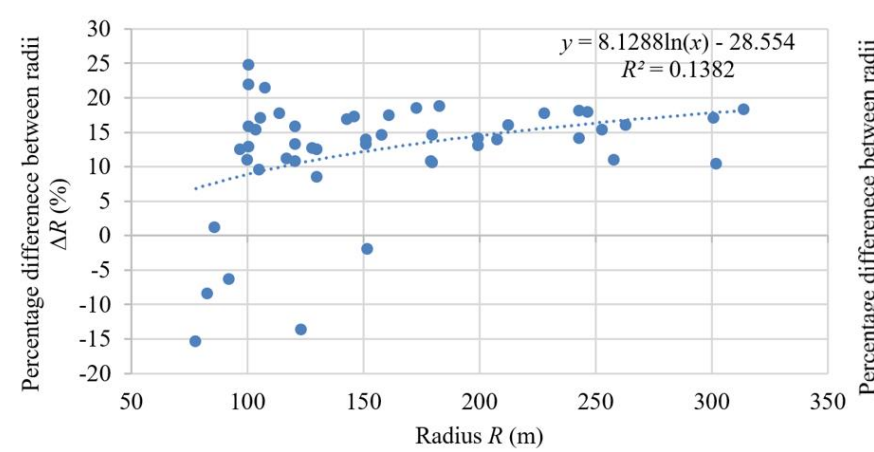

a)

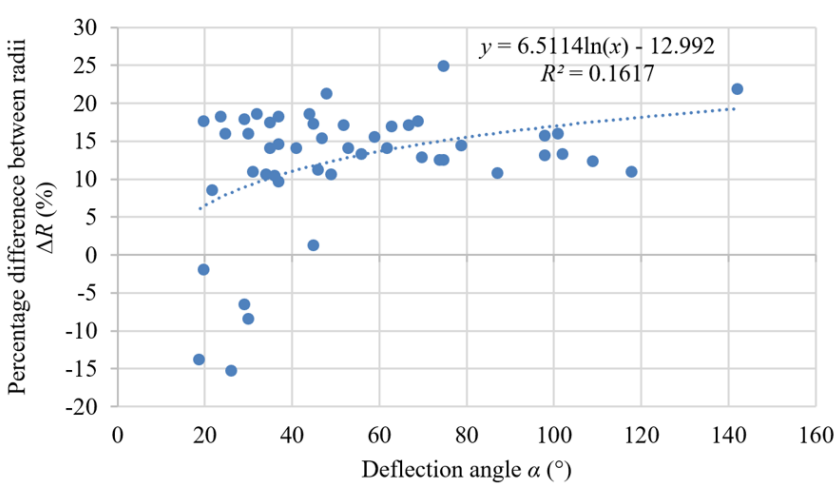

c)

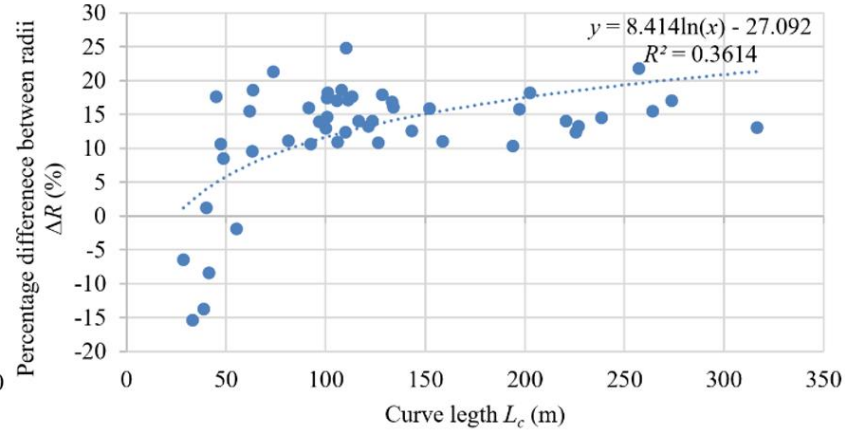

b)

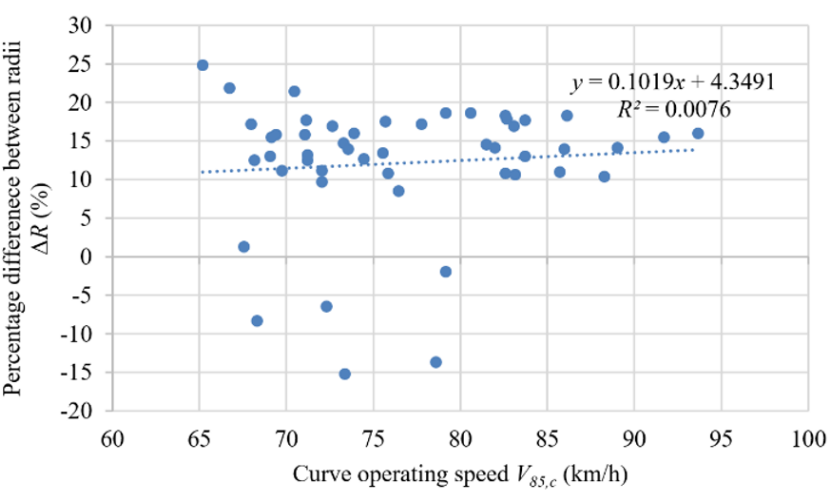

d)

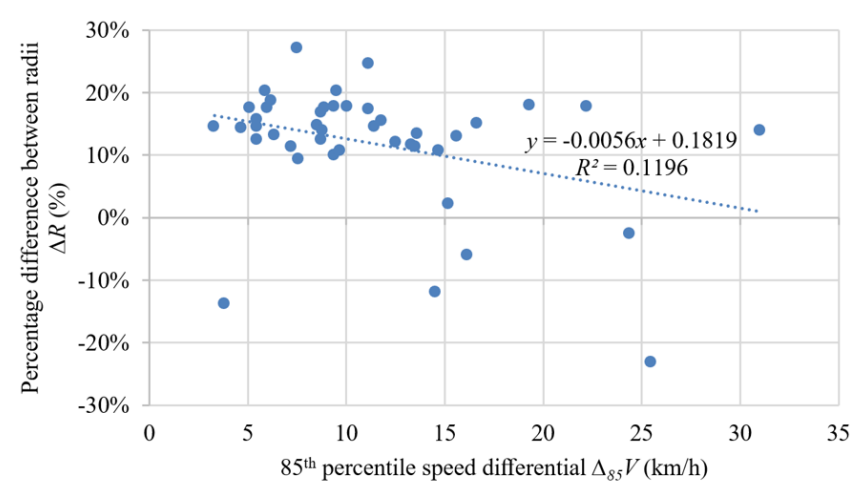

e)

Fig. 3. Individual scatter plots of percentage difference between radii versus: a) curve radius; b) curve length; c) deflection angle; d) curve operating speed; e) speed differential (north-south direction) [10]

\section{Conclusions}

Traffic accident statistics, according to which horizontal curves (especially sharp curves) are high-risk locations, present a fundamental motivation for this research. Accidents usually occur due to lack of design consistency. Most of previous design consistency and road safety studies were based on operating speed whereas only a few of them were analysing the consistency in curves in terms of vehicle path radii. Under this scope, the main objective of this paper was to analyse the conformance of the road geometry with the drivers' behaviour, by comparing curve radii and critical 15 th percentile vehicle path radii. Continuous data recording methodology, based on GPS device, was used to collect the driver behaviour data on a segment of the two-lane state road. Differences between radii were observed and it was attempted to find the possible causes of these deviations. Using stepwise regression analysis, it was analysed whether the speed, speed differential and geometric characteristics of the road affect the driver's choice of path radius. Although the performed analysis did not result in a statistically significant model, it was found that drivers generally track vehicle path in sharper curvature than that of road alignment, regardless of driving direction. The vehicle path radii were on average $12 \%$ smaller than curve radius. Additionally, higher differences in curvature were observed on sharper curves, whereas smaller radius of vehicle path causes greater centripetal acceleration, i.e., increased side friction demand. Therefore, in poor road conditions and speed not adjusted to the curve geometry, the loss of lateral vehicle stability can easily occur in sharp curves and potentially lead to traffic accident. 
Finally, the most important conclusion of the present paper is the fact that the cause of single-vehicle accidents on curves, which are common and usually occur due to loss of vehicle control or stability as a result of exceeding the available values of side friction, cannot be attributed only to inappropriate speed. The cause can also be found in the drivers' behaviour in terms of vehicle trajectory or drivers' inability to maintain lane position. The results of this paper can be used to improve design consistency measure regarding to the vehicle stability. Since the existing vehicle stability procedure is based on the assumption that the driver's path radii are equal to the curve radius, it is logical to use the value of vehicle path radius when calculating side friction demand, to more realistically predict lateral vehicle inconsistency. Considering that the critical vehicle path radius $12 \%$ lower than curve radius was observed in this research, it is proposed to use this value when calculating the margin of safety. Smaller values of curve radii would result in lower margins of safety and thus inconsistencies would be much easier detected and eliminated. Therefore, horizontal curves of the final road design would represent the satisfactory level of consistency even in real conditions for the majority of drivers. Designing horizontal curves that are consistent with driver behaviour is a base to achieving safer roads.

Limitations of the present research relate to the size of the driver sample that cannot be considered sufficient for reaching wider applicable results. In addition, it should be pointed out that the analysed section was designed several decades ago when, according to the former guidelines, the use of spirals was not obligatory. Therefore, in most of the cases, there is no spiral transition between tangent and circular curve or there is a short one (mostly lengths from 20 to $30 \mathrm{~m}$ ). This absence of spirals or the application of very short ones might have had the negative impact on the driver's choice of path radius because the driver failed to adjust both, speed and path radius. So, it would be interesting to analyse the driver's behaviour on sections with spiral transitions of sufficient lengths. In addition, future work may focus on collecting more data, covering a larger sample of drivers and test drives from several different road sections (i.e., from different areas). More representative sample of drivers and larger number of road sections would result in a more detailed and comprehensive analysis of the design consistency in horizontal curves.

\section{Acknowledgments}

This research was partially supported through project KK.01.1.1.02.0027, co-financed by the Croatian Government and the European Union through the European Regional Development Fund - the Competitiveness and Cohesion Operational Programme.

\section{References}

[1] Bartunek, M., Moravcik, O. \& Schreiber, P. (2011). Safety distance for vehicles through simulation. In Annals of DAAAM for 2011 \& Proceedings of the 22nd International DAAAM Symposium, Volume 22, No. 1, ISSN 17269679, ISBN 978-3-901509-83-4, Editor B. Katalinic, Published by DAAAM International, Vienna, Austria.

[2] PIARC World Road Association (2003). Road Safety Manual.

[3] Lamm, R., Psarianos, B. \& Mailaender, T. (1999). Highway design and traffic safety engineering handbook, McGraw-Hill, ISBN 0-07-038295-6, New York, United States.

[4] Said, D., Abd El Halim, A. O., Hassan, Y. (2009). Methodology for driver behaviour data collection and analysis for integration in geometric design of highways, Proceedings of the 4th International Symposium on Highway Geometric Design, June 2.-5. 2009; Valencia, Spain.

[5] Fitzsimmons, E. J. et al. (2013). Determining vehicle operating speed and lateral position along horizontal curves using linear mixed-effects models, Traffic Injury Prevention, 14(3): 309-321. DOI: 10.1080/15389588.2012.701356.

[6] Wong, Y. D., Nicholson, A. (1993). Speed and lateral placement on horizontal curves, Road and Transport Research, 2(1): 74-87.

[7] Wong, Y. D., Nicholson, A. (1992). Driver behaviour at horizontal curves: risk compensation and the margin of safety, Accident Analysis and Prevention, 24(4): 425-436. DOI: 10.1016/0001-4575(92)90053-L.

[8] Glennon, J. C., Weaver, G. D. (1972). Highway curve design for safe vehicle operations, Highway Research Record, 390; 15-26.

[9] Glennon, J. C., Neuman, T. R., Leisch, J. E. (1983). Safety and operational considerations for design of rural highway curves, Report FHWA-RD-86-035, Federal Highway Administration, U. S. Department of Transportation, Washington, DC, 1983.

[10] Maljković, B. (2021). Unapređenje kriterija konzistencije u horizontalnim krivinama vangradskih dvotračnih cesta uz primjenu bicikl-modela vozila te realnih parametara ponašanja vozača, dokstorska disertacija (Evaluation of design consistency on horizontal curves for two-lane state roads using bicycle-model and realistic parameters of driver behaviour), Ph.D. Dissertation, Department of Transportation Engineering, University of Split, Faculty of Civil Engineering, Architecture and Geodesy, Split, Croatia.

[11] Carlson, P. J., Burris, M., Black, K., Rose, E. R. (2005). Comparison of radius-estimating techniques for horizontal curves, Transportation Research Record, 1918(1): 76-83. DOI: 10.3141/1918-10.

[12] Nicholson, A. (1998). Superelevation, side friction, and roadway consistency, Journal of Transportation Engineering, 124(5): 411-418. DOI: 10.1061/(ASCE)0733-947X(1998)124:5(411). 